\title{
Savings test for associations between neutral stimuli
}

\author{
PETER C. HOLLAND and ROBERT T. ROSS \\ University of Pittsburgh, Pittsburgh, Pennsylvania
}

\begin{abstract}
Three experiments showed a savings procedure to be an effective and sensitive alternative to sensory preconditioning procedures as a measure of associations among neutral stimuli. Experiment 1 showed that within-compound associations developed more rapidly in reinforced appetitive serial compound conditioning when nonreinforced preexposure to the serial compound was given than when separate element or no preexposure was given. Experiment 2 showed the savings effect to be highly stimulus specific. Experiment 3 examined the facilitation of serial compound conditioning after either simultaneous or serial nonreinforced preexposure to the elements of the compound. The results of that experiment were consistent with those of analogous sensory preconditioning experiments. When preexposure involved only the two elements of the subsequently reinforced compound, serial preexposure produced more savings than simultaneous preexposure. But when preexposure involved a three-stimulus procedure like that used by Rescorla (1980b), simultaneous preexposure resulted in more savings. Advantages of the savings procedure over sensory preconditioning as a measure of association among neutral stimuli are discussed.
\end{abstract}

There has been renewed interest in the establishment of associations between relatively neutral stimuli. Much of this interest can be attributed to several recent demonstrations that such associations are readily formed (e.g., Lavin, 1976; Rescorla, 1980a; Rescorla \& Cunningham, 1978) and may importantly affect performance in standard compound conditioning situations. For example, Kaplan and Hearst (1982), Kehoe, Gibbs, Garcia, and Gormezano (1979), and Pearce, Nicholas, and Dickinson (1981) attributed the potentiation of conditioned responses evoked by S1 in S1-then-S2-thenUS serial compound conditioning relative to those evoked by $\mathrm{S} 1$ in S1-trace-US conditioning to the acquisition of associations between $\mathrm{S} 1$ and $\mathrm{S} 2$. Although in the serial compound conditioning situations studied by those investigators $\mathrm{S} 1$ did not occur in an ideal temporal location for the acquisition of first-order associations between it and the US, it did occur in a favorable conditioning relation with an S2 that was more contiguous with US delivery. Thus, responding to S1 could occur as a consequence of second-order or sensory conditioning (e.g., Gormezano \& Kehoe, in press). Similarly, Rescorla and his colleagues have argued that withincompound associations are responsible for the po-

This research was supported in part by Grant BNS 79-03853 from the National Science Foundation. Some of these data were reported at the April 1982 meeting of the Eastern Psychological Association in Baltimore, Maryland. P. C. Holland's mailing address is: Department of Psychology, University of Pittsburgh, Pittsburgh, Pennsylvania 15260. R. T. Ross is now at the University of Iowa. Reprints are not available. tentiation of odor-aversion conditioning (Durlach \& Rescorla, 1980), incomplete blocking (Speers, Gillan, \& Rescorla, 1980), incomplete transfer of inhibition (Rescorla, 1982), and other phenomena (e.g., Rescorla, 1980a).

The most common procedure for studying associations among relatively neutral stimuli is sensory preconditioning. In a typical sensory preconditioning experiment, two stimuli ( $\mathrm{S} 1$ and $\mathrm{S} 2$ ) are first presented jointly, then responding to one of them (S2) is altered (usually by pairing it with a US), and, finally, responding to the other stimulus (S1) is assessed. Associations between $\mathrm{S} 1$ and $\mathrm{S} 2$ are inferred if responding to $S 1$ is also found to be altered. That procedure demands, however, that the subject not only associate two neutral stimuli but also integrate or "chain together" two separate associations acquired at different times and in different contexts of reinforcement (cf. Adams \& Dickinson, 1981). Furthermore, Rescorla (1980a) has claimed that presentation of $S 2$ in the absence of $S 1$, as in the second phase of a sensory preconditioning experiment, can destroy previously acquired S1-S2 associations.

The experiments described here demonstrated the usefulness of a somewhat different test for the formation of associations between neutral stimuli. In three experiments involving the direct observation of the behavior of rat subjects, the paired presentation of neutral visual and auditory stimuli in a preexposure phase was followed by Pavlovian appetitive serial compound conditioning of the form visual CS (V)-auditory CS (A)-food. Associations 
formed during the nonreinforced preexposure phase were reflected in the more rapid acquisition of responding to the visual CS during the reinforced compound conditioning phase. This savings procedure avoids both problems inherent in sensory preconditioning experiments: since the relation between $V$ and $A$ is maintained throughout the experiment, integration of associations acquired at different times and in different reinforcement contexts is not required, and the stimulus elements are never presented individually.

Using the same conditioning preparation that was used in the present experiments, Holland and Ross (1981) found that the formation of associations between the elements of a reinforced serial compound CS altered the topography of conditioned responding to those elements. In that preparation, rats typically perform topographically distinct CRs to CSs of different modalities (e.g., Holland, 1977). Visual CSs paired with food generally evoke rearing and food cup entry but auditory CSs evoke an initial startle response followed by rapid head movements that we termed "head jerk" responding. However, when a visual-then-auditory serial compound was paired with food in Holland and Ross's experiments, a different pattern of responding ensued. Perhaps the most important observation was that the visual stimulus acquired the ability to evoke headjerk behavior normally evoked only by auditory CSs. Comparisons with performance in control conditions in which the visual and auditory stimuli were each paired with food but not with each other showed that the acquisition of head-jerk behavior to the visual S1 was dependent on the pairing of visual and auditory stimuli. Further experiments indicated that associations between the visual S1 and fairly detailed stimulus properties of the auditory S2 were responsible for the acquisition of that behavior tendency. For example, in one experiment (Holland \& Ross, 1981, Experiment 3), two visual-auditory serial compounds, V1-A1 and V2-A2, were paired with food. Then the rats received $\mathrm{A} 1+, \mathrm{A} 2-$ discrimination training designed to maintain A1's ability to evoke CRs but to eliminate responding to $A 2$. Final testing of responding to V1 and V2 alone showed that V2's ability to evoke head-jerk behavior had been lost but that V1 still generated substantial amounts of that behavior. Thus, apparently the ability of visual stimuli within visual-auditory serial compounds to evoke head-jerk behavior depended on their association with representations of subsequent auditory CSs that themselves evoked that behavior. (See Holland, in press, and Ross \& Holland, 1981,1982 , for additional evidence for this claim.)

The experiments reported here exploited Holland and Ross's (1981) findings to investigate the formation of associations among neutral visual and au- ditory stimuli. The establishment of light-tone associations in a preexposure phase was indexed by the more rapid acquisition of head-jerk behavior to the light in subsequent light-tone-food serial conditioning. Experiment 1 showed that paired lighttone preexposure facilitated the acquisition of headjerk behavior to the light in light-tone-food serial compound conditioning. Experiment 2 examined the stimulus specificity of the facilitatory effect observed in Experiment 1, and Experiment 3 compared the effects of simultaneous and serial presentations of the light and tone in the preexposure phase on the magnitude of the facilitation effect.

\section{EXPERIMENT 1}

Considerable evidence indicates that the serial pairing of two stimuli in the absence of reinforcement can result in the formation of associations between those events (e.g., Rizley \& Rescorla, 1972; Thompson, 1972). In Experiment 1, separate groups of rats received serial light-tone-food conditioning after either nonreinforced presentations of that same light-tone compound, nonreinforced presentations of the light and tone separately, or mere exposure to the conditioning chamber. If the acquisition of head jerk to the light during serial conditioning reflects the existence of light-tone associations, then the rats that received prior nonreinforced serial compound presentations should have acquired that behavior more rapidly than the other two groups, since those presentations presumably would have provided additional opportunity to acquire light-tone associations.

\section{Method}

Subjects and Apparatus. The subjects were 24 female SpragueDawley rats about 150 days old at the beginning of the experiment. Eight rats were experimentally naive and 16 had previously been subjects in a flavor-aversion conditioning experiment involving water deprivation, injection of lithium chloride, and delivery of sucrose, salt, and lemon-flavored solutions. Naive and experienced rats were distributed among the groups of Experiment 1 as evenly as possible. The rats were maintained at $80 \%$ of their ad-lib body weights throughout the experiment by limiting their access to food.

Four experimental chambers, each $22.9 \times 20.3 \times 20.3 \mathrm{~cm}$, were used. The two end walls of each chamber were aluminum and the side walls and top were clear acrylic. A food cup was recessed in the center of one end wall; a 6-W jeweled panel light $6 \mathrm{~cm}$ above the food cup provided general illumination. The chamber floors were made of $.48-\mathrm{cm}$ stainless steel rods spaced $1.9 \mathrm{~cm}$ apart. Each experimental chamber was enclosed in a soundresistant shell that contained speakers for delivering auditory stimuli and a normally off $6-W$ houselight that served as one of the conditioned stimuli. The front wall of each shell contained an acrylic window to permit behavioral observations. A low-light television camera was mounted $2.1 \mathrm{~m}$ from the experimental chambers to include all four chambers in its field of view. A videocassette recorder was programmed to record behaviors occurring during, and 10 -sec before and after, CS presentations. 
Behavioral observation procedures. All observations were made from videotapes. Each rat's behavior was observed at 1.25 $\mathrm{sec}$ intervals during the 10 -sec period immediately prior to CS presentations and during the CS presentations. The observations were paced by auditory signals recorded on the videotapes. On each observation, one and only one behavior was recorded. Four behavioral categories were reported: rear-standing on hindlegs with both front feet of the floor; magazine-standing motionless in front of the food magazine with head or nose within the recessed food cup; head jerk-short, rapid horizontal and/or vertical movements, usually (but not necessarily) directed toward the side of the chamber that contained the food cup; and quietgrooming, sniffing, sleeping, gnawing the grid bars, and other activities (see Holland, 1977, for a more complete description). Startle behavior, which usually occurs in response to auditory CSs paired with food (Holland, 1977), did not occur in the conditioning phases of these experiments. Holland and Ross (1981) noted that auditory stimuli trained within visual-then-auditory stimulus compounds did not evoke that response. We attributed the suppression of startle responding under those circumstances to light-tone associations: presumably, only a surprising tone would be able to evoke a startle response.

Procedure. The rats first received two $70-\mathrm{min}$ preexposure sessions. In each of those sessions, the rats in Group $P$ received six serial compound presentations consisting of a 5-sec flashing $(2 / \mathrm{sec})$ of the houselight followed immediately by a 5 -sec $1,500-\mathrm{Hz}$ tone. The rats in Group $\mathrm{U}$ received six 5 -sec flashing light presentations and six $5-\sec 1,500-\mathrm{Hz}$ tones, explicitly unpaired, in each of those sessions. The rats in Group $\mathbf{N}$ were placed in the experimental chambers for those two sessions, but no events were presented. Next, all rats received a single 20 -min magazine training session in which eight two-pellet USs $(45-\mathrm{mg}$ food pellets) were delivered at random intervals. Finally, all rats received eight 70-min serial conditioning sessions, each containing eight serial compound trials. A serial compound trial consisted of the presentation of the 5-sec flashing light followed immediately by the $5-\mathrm{sec} 1,500-\mathrm{Hz}$ tone, which terminated in the delivery of two food pellets.

The $\mathrm{p}<.05$ level of statistical significance was adopted.

\section{Results and Discussion}

During the two preexposure sessions, little behavior other than quiet was observed. In all three groups, $17 \%$ of all behavior during the pre-CS periods was magazine behavior. During the light presentations, $16 \%$ of all behavior was rear and $15 \%$ was magazine in Group P; in Group $U$, there was $19 \%$ rear and $17 \%$ magazine. Magazine behavior in the presence of the tone accounted for $17 \%$ of total behavior in both Groups P and U. All other behavior was quiet; no head-jerk behavior was observed during the preexposure sessions in any group.

Figure 1 shows the acquisition of head-jerk behavior to the light $\mathrm{CS}$ during the serial conditioning phase. To be consistent with the data analyses used in Experiments 2 and 3, in which only four serial conditioning sessions were administered, statistical analyses were performed separately for the first four and last four conditioning sessions in Experiment 1 . Results of the analyses of the two blocks of sessions were similar, although some of the analyses of the last four sessions yielded higher $p$ values. Only the analyses of the first block of four sessions are presented here. The three groups differed in the

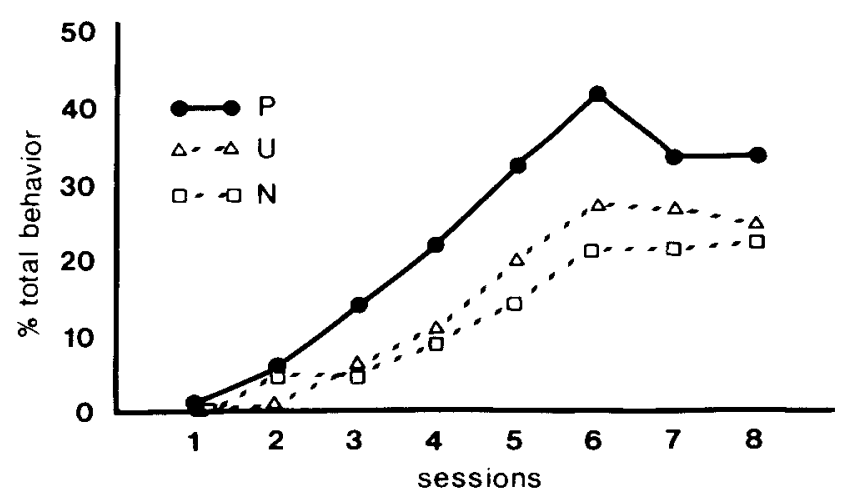

Figure 1. Mean percentage head-jerk behavior to the visual S1 during the serial conditioning phase of Experiment 1.

frequency of head-jerk behavior to the light $[F(2,21)$ =3.6]. Group $P$ showed significantly more of that behavior than did either of the other groups $[\mathrm{Fs}(1,21)$ $=4.80$ ], which did not differ from each other $(F=0)$. Thus, acquisition of head-jerk behavior to the light, earlier attributed to the presence of light-tone associations, was facilitated by prior nonreinforced pairings of the light and the tone. In fact, those nonreinforced pairings may have been at least as effective in establishing light-tone associations as an equal number of reinforced light-tone pairings early in training. During the 16 trials of the third and fourth serial conditioning days following 28 light-tone trials (12 nonreinforced trials and 16 reinforced), Group $P$ showed $18 \%$ head-jerk behavior to the light. But during the 16 conditioning trials following the first 28 light-tone trials (all reinforced), Group $\mathrm{N}$ showed $12 \%$ head-jerk behavior to the light. Although this difference was not reliable $[t(14)=1.10]$, it does indicate that reinforced light-tone pairings were no more effective in establishing associations than nonreinforced pairings (see also Rescorla, 1981).

It might be suggested, however, that although the facilitation observed was a function of lighttone preexposure, it was not necessarily due to the formation of light-tone associations in that phase. Lubow, Schnur, and Rifkin (1976) found that presentation of a serial compound produced less latent inhibition to its elements than did separate presentation of those elements. Perhaps the differences in responding to the light in Experiment 1 were due to variations in latent inhibition to either the light or the tone rather than to variations in light-tone association. However, several features of the data argue against that interpretation. First, the differential responding to the light $\mathrm{S} 1$ was not attributable to differences in conditioning to the tone among the groups. The frequency of head-jerk behavior to the tone was similar in the three groups $[F(2,21)$ $=1.32]$, constituting $43.2 \%, 31.2 \%$, and $43.0 \%$ of the total behavior to the tone in Groups $P, U$, 
and $\mathrm{N}$, respectively. More important, responding to the light in Group $\mathbf{P}$ was greater than that in Group N, which had no opportunity for latent inhibition. Finally, there was no evidence that twelve preexposures of the light and the tone were sufficient to produce latent inhibition, even in Group U. Neither responding to the light nor responding to the tone differed reliably between Group $U$ and Group N. Previous unpublished experiments in this laboratory suggested that at least 20 preexposures may be necessary to produce consistent latent inhibition with conditioning parameters reasonably comparable to those used here. Hence, the facilitated acquisition of head-jerk behavior to the light in Group $P$ apparently reflected the establishment of associations between the light and tone during the preexposure phase, rather than variations in the amount of latent inhibition.

Rear behavior to the light also differed among the groups, although not significantly so $[F(2,21)$ $=2.90, p<.10$ ]. Individual comparisons showed that Group $P$ exhibited reliably less rear behavior $(18.4 \%)$ than Group $U[40.0 \% ; F(1,21)=5.80]$, but not than Group $N[29.7 \% ; F(1,21)=1.45]$. Previous evidence suggests that rear behavior is indicative of first-order light-food associations and/or second-order associations between the light and the emotional response to the tone (e.g., Holland, in press; Holland \& Ross, 1981). Thus, prior nonreinforced light-tone presentations may have altered the contents of subsequent serial compound conditioning, allowing light-tone associations to play a greater than normal role at the expense of associations between the light and other events (see Rescorla, 1980a, for examples of such competition for associations). But the present data do not permit us to rule out a simpler alternative, namely, that the occurrence of head-jerk behavior to the light in Group P simply prevented the display of rear behavior in performance. For this reason, rear behavior data are not presented in Experiments 2 and 3. In general, however, head-jerk and rear behavior were inversely related in those experiments as well.

\section{EXPERIMENT 2}

Holland and Ross (1981, Experiment 3, described above) found within-compound associations in reinforced serial compound conditioning to be highly stimulus specific in this preparation. Experiment 2 examined the stimulus specificity of the savings effect observed in Experiment 1. If the associations established during preexposure of serial compounds contained information about the particular elements of those compounds, then subsequent serial compound conditioning should have been facilitated only if the reinforced and preexposed compounds were identical. The rats first received nonreinforced preexposure to two serial compound stimuli, V1-A1 and V2-A2. Then half of the rats received foodreinforced serial compound conditioning that was either congruent (i.e., V1-A1-food and V2-A2-food) or incongruent (V1-A2-food and V2-A1-food) with their preexposure treatment.

\section{Method}

Subjects and Apparatus. The subjects were 16 female SpragueDawley rats about 150 days old at the beginning of the experiment. All of the rats had previously been subjects in a flavoraversion conditioning experiment. The rats were maintained at $80 \%$ of their ad-lib body weights by limiting their access to food.

The apparatus was that used in Experiment 1, except that general illumination was provided by an infrared lamp mounted $3 \mathrm{~m}$ from the chambers, rather than by the 6-W lamp that was mounted over the food magazine. The latter lamp ("signal lamp") was used as a $\mathrm{CS}$ in Experiment 2.

Procedure. The rats first received three 70 -min preexposure sessions. Each session contained four nonreinforced presentations of each of two different serial visual-auditory compounds, randomly intermixed. For half of the rats, one compound consisted of a 5-sec continuous illumination of the houselight followed immediately by a 5-sec continuous presentation of a 1,500$\mathrm{Hz}$ tone, and the other compound consisted of a 5-sec intermittent $(2 / \mathrm{sec})$ illumination of the signal light followed by a $5-\mathrm{sec}$ intermittent $(3 / \mathrm{sec})$ white-noise presentation. For the other half of the rats, one compound was a 5 -sec continuous houselight followed by the 5 -sec intermittent noise, and the other compound was a 5-sec intermittent signal light followed by a 5-sec continuous $1,500-\mathrm{Hz}$ tone. Next, all rats received a single $20-\mathrm{min}$ magazine training session in which eight two-pellet USs were delivered at random intervals. The rats then received four 70 -min sessions of food-reinforced serial compound conditioning that was either congruent (Group C) or incongruent (Group I) with their preexposure training. In each conditioning session, the rats in Group $C$ received four reinforced presentations of each of the two compounds they had received in the preexposure phase, randomly intermixed. The rats in Group 1 received in each conditioning session four reinforced presentations of each of the compounds that they had not received during preexposure. Thus, a rat in Group $C$ that had been preexposed to the houselight-noise and the signal light-tone compounds received reinforced presentations of those same compounds, but a rat in Group I that had been preexposed to those compounds received reinforced presentations of the houselight-tone and signal lightnoise compounds. Half of the rats in each group were those that had received preexposure to the houselight-tone and signal light-noise compounds, and half were those that had been preexposed to the houselight-noise and signal light-tone compounds.

\section{Results and Discussion}

As in Experiment 1, little behavior other than quiet was observed in the preexposure phase. Preliminary analysis of the serial conditioning phase data showed that the choice of compounds used (i.e., houselight-noise and signal light-tone vs. houselight-tone and signal light-noise) had no effect. Furthermore, within each group, responding to the two compounds did not differ. Figure 2 shows the acquisition of head-jerk behavior to the visual S1s (combined) in Group C and Group I during the serial conditioning phase. Over the four sessions, Group C showed significantly more head-jerk behavior to 


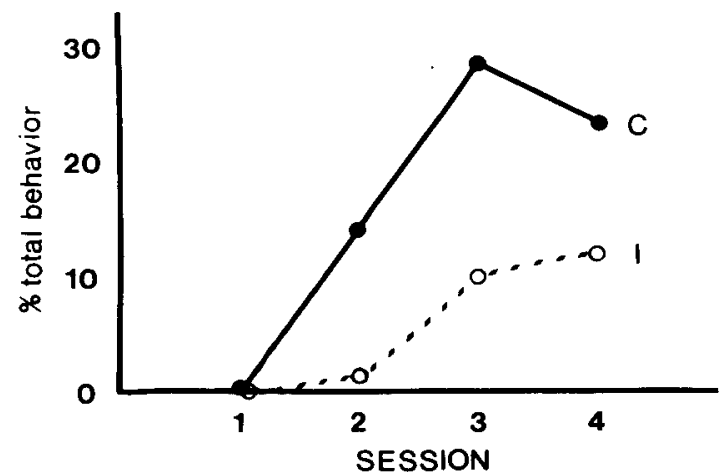

Figure 2. Mean percentage head-jerk behavior to the visual S1 during the serial conditioning phase of Experiment 2.

the visual S1s than did Group I $[t(14)=2.61]$. The lack of any reliable difference in the frequency of head-jerk behavior to the auditory S2s [Group C $=38.5 \%$ and Group $I=36.2 \% ; t(14)=.55]$ indicates that the differences in responding to the visual S1s between the two groups were due to differential visual-auditory associations rather than to different levels of conditioning to the auditory S2.

The greater savings in acquisition observed in Group $C$ in this experiment indicates both that the associations established among the various neutral stimuli involved fairly detailed representations of those events, and that the savings test procedure is sufficiently sensitive to detect that detail. Furthermore, note that, since in both groups all stimuli were preexposed as elements within stimulus compounds, the differential savings observed in the two groups could not be attributed to latent inhibition effects.

\section{EXPERIMENT 3}

Experiments 1 and 2 indicated that the savings procedure provides an effective assessment of association between neutral stimuli. Experiment 3 used that procedure to examine how the strength of such associations is affected by the temporal arrangement (serial vs. simultaneous presentation) of those events during the preexposure phase.

Investigations of both sensory preconditioning (e.g., Thompson, 1972; Wickens \& Cross, 1963; but see Lavin, 1976) and standard conditioning procedures (see Mackintosh, 1974) have found greater conditioned responding after serial than after simultaneous pairing of events. Rescorla (1980b) noted, however, that such comparisons are biased in favor of observing a superiority of serial event presentations. He pointed out that with simultaneous presentations, $S 1$ is presented within a compound, but with serial presentations, $S 1$ is presented alone. Consequently, in the serial case, S1 may be better processed or attended to, enabling it to bet- ter enter into associations with $\mathbf{S 2}$, regardless of its temporal relations with that stimulus. Furthermore, since responding indicative of $\mathrm{S} 1-\mathrm{S} 2$ associations is assessed in the presence of $\mathrm{S} 1$ alone in testing, subjects that received serial presentations in training might undergo substantially less generalization decrement than subjects that received simultaneous presentations. To circumvent those problems, Rescorla used a preexposure procedure in which S1 was presented within a compound with both serial and simultaneous arrangements. All subjects received an S1S2 compound followed immediately by a separate presentation of $\mathrm{S}^{\prime}$. He then compared the strength of S1-S2 (simultaneous) and S1-S2' (serial) associations using a sensory preconditioning procedure. That is, after conditioning either S2 or $\mathrm{S}^{\prime}$ ', responding to $\mathrm{S} 1$ alone was assessed. Responding to S1 after S2 training would reflect S1's simultaneous associations and responding to $S 1$ after S2' training would reflect S1's serial associations.

Experiment 3 compared the effectiveness of simultaneous and serial presentations of events in the formation of associations between neutral visual and auditory stimuli, using both Rescorla's three-stimulus technique and traditional two-stimulus procedures. As in Experiments 1 and 2, the measure of association between the neutral stimuli was savings in the acquisition of head-jerk behavior to a visual $S 1$ in subsequent S1-S2-food conditioning. Rats in the three-stimulus groups received preexposure to a VA-A' sequence. The strength of simultaneous association was measured by examining the rate of acquisition of head-jerk behavior to $V$ during serial V-A-food conditioning, and the strength of V's serial association was assessed by examining responding in serial $\mathbf{V}-\mathrm{A}^{\prime}$-food training. Rats in the two-stimulus groups received preexposure to either a VA simultaneous compound or a V-A sequence, and then received $\mathrm{V}$-A-food training.

\section{Method}

Sabjects and Apparatus. The subjects were 24 male and 24 female Sprague-Dawley rats about 150 days old at the start of the experiment. The sexes were equally distributed among the groups. Three rats were experimentally naive, and the other 45 had been subjects in flavor-aversion conditioning experiments. Assignment of the rats to groups in Experiment 3 was orthogonal to their prior experimental treatments. The apparatus was that used in Experiment 1.

Procedure. First, the rats received six nonreinforced compound stimulus presentations in each of two 70-min preexposure sessions. Those compounds consisted of a 5 -sec intermittent $(2 / \mathrm{sec})$ illumination of the houselight (V) followed immediately by a 5 -sec auditory stimulus $(A)$ in Group Ser-2 $(n=8)$, and of 5 sec of simultaneous $V$ and $A$ in Group Sim-2 $(n=8)$. In Groups Ser-3 and Sim-3 (ns=16), they consisted of $5 \mathrm{sec}$ of simultaneous $\mathrm{V}$ and one auditory stimulus (A) followed immediately by a 5 -sec presentation of another auditory stimulus $\left(A^{\prime}\right)$. For half of the rats in each group, $A$ was the $1,500-\mathrm{Hz}$ tone and $A^{\prime}$ was the white noise; for the other half, $A$ was the noise and $A^{\prime}$ was the tone. Thus, in this phase, the rats in Groups 
Ser-2, Sim-2, Ser-3, and Sim-3 received stimulus presentations of the form V-A, VA, VA-A', and VA-A', respectively. Next, all of the rats received magazine training like that in Experiments 1 and 2. Finally, all rats received four serial compound savings test sessions, each of which contained eight reinforced serial compound presentations. In Groups Ser-2, Sim-2, and Sim-3, those compounds were of the form V-A-food; in Group Ser-3, they were V-A'-food.

\section{Results and Discussion}

As in Experiments 1 and 2, there was little behavior other than quiet during the preexposure phase. Figure 3 shows the acquisition of head-jerk behavior to the light S1 during the serial conditioning phase. Savings was greater (i.e., acquisition was more rapid) in Groups Sim-3 and Ser-2 than in Groups Sim-2 and Ser-3. Thus, as in earlier sensory preconditioning studies using the conventional twostimulus procedures (e.g., Wickens \& Cross, 1963), serial preexposure of the light and tone led to stronger evidence for association than simultaneous presentation. But when three-stimulus procedures designed to minimize confounding effects of differential attention and generalization decrement were used, greater savings was observed with simultaneous presentation of those stimuli. Hence, the data of Groups Sim-3 and Ser-3 extend Rescorla's (1980b) findings to an appetitive conditioning situation and a savings test of association among neutral stimuli. Since the reinforced compound conditioning (test) phase in Experiment 3 demanded that the rats from associations between serially presented visual and auditory stimuli, it is especially impressive that simultaneous, rather than serial, preexposure to those events led to greater savings in the acquisition of head-jerk behavior to the light.

This description of the data was supported by a two-way unweighted means analysis of variance of the data from the four serial conditioning sessions, with temporal sequence (simultaneous vs. serial) of the preexposure to light and tone as one factor and two- vs. three-stimulus preexposure procedures as the other factor. Neither main effect was reliable

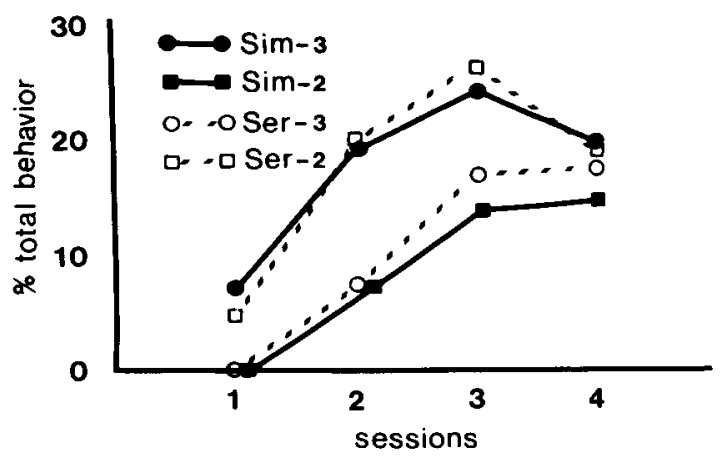

Figure 3. Mean percentage head-jerk behavior to the visual S1 during the serial conditioning phase of Experiment 3 .
(Fs $<1)$, but their interaction was significant $[F(1,44)$ $=15.80]$. Subsequent tests of the simple main effects (i.e., individual paired comparisons) showed a reliable effect of temporal sequence with both two-stimulus (Ser-2 vs. Sim-2) $[F(1,44)=11.18]$ and three-stimulus (Sim-3 vs. Ser-3) $[F(1,44)=5.19]$ procedures, and a reliable effect of preexposure procedure with both serial (Ser-2 vs. Ser-3) $[F(1,44)$ $=6.37]$ and simultaneous (Sim-3 vs. Sim-2) $[F(1,44)$ $=9.59$ ] sequences. More conservative Scheffé tests found all of these differences to be reliable at the $\mathrm{p}<.10$ level, but only the Ser-2 vs. Sim-2 and Sim-3 vs. Sim-2 comparisons were significant at the $p<$ .05 level.

As in Experiments 1 and 2, the differences among the groups in head-jerk behavior to the light were apparently due to differences in the strength of lighttone associations, rather than to differences in the strength of the tone S2. The percentages of total behavior that was head jerk were $38.3 \%, 46.6 \%$, $49.3 \%$, and $44.9 \%$ in Groups Sim-2, Ser-2, Sim-3, and Ser-3, respectively. An analysis of variance like that described above showed no reliable main effects $[F s(1,44)<1.19$, or interaction, $F(1,44)=2.40]$.

The simplest account for the differential effects of the two- and three-stimulus procedures is that simultaneous stimulus presentation generates stronger association than a serial arrangement (Group Sim-3 $>$ Group Ser-3) but that in two-stimulus procedures the superiority of simultaneous association is overpowered by the occurrence of greater competition for processing of $\mathrm{V}$ at the time of training and/or greater generalization decrement from training to testing (Group Ser-2 > Group Sim-2). By the same logic, the superiority of Group Ser-2 to Group Ser-3 observed here is expected, since the three-stimulus serial procedure would involve greater competition for processing and generalization decrement than the corresponding two-stimulus procedure. However, it is not clear from this account why Group Sim-3 should generate greater association than Group Sim-2. The same simultaneous relation was arranged between $\mathbf{V}$ and $\mathbf{A}$ in both groups, and both involved similar change in context of $V$ presentation from training to test and similar competition for processing of $\mathrm{V}$. In fact, some theories (e.g., Wagner, 1978) and data (e.g., Holland, 1980; Rescorla, 1981) suggest that the postcompound presentation of $A^{\prime}$ in Group Sim-3 would be likely to interfere with the formation of $\mathrm{V}$-A associations.

Since the two- and three-stimulus procedures have not been directly compared elsewhere, it remains to be seen whether the pattern of data observed here is typical. It is interesting to speculate that the two procedures may encourage different kinds of learning. Rescorla (1980b) suggested that simultaneous stimulus presentation may in some cases result in 
the formation of a representation of that compound or configuration that can be activated by either of its constituent elements alone, at the expense of the associations typically assumed to be formed between individual representations of serially presented stimuli. On the other hand, other recent data indicate that repeated reinforced (e.g., Gillette \& Bellingham, 1982) or nonreinforced (e.g., Forbes, 1981) presentations of a compound may reduce the ability of its elements to activate such a compound representation, a phenonenom known as "spontaneous configuring" (e.g., Razran, 1971). Furthermore, Forbes (1981) noted that presentation of another event immediately after compound presentation (as in VA- $A^{\prime}$ presentations) can disrupt such spontaneous configuring. It is conceivable that the occurrence of spontaneous configuring in Group Sim-2 prevented V from activating the VA compound representation in that group, but that the presentation of $A^{\prime}$ disrupted spontaneous configuring in Group Sim-3, thus permitting $V$ to maintain its power to activate the VA compound representation. Resolution of the discrepancies between the results of two- and three-stimulus procedures may lead to new thoughts about the so-called "associative" processes involved in compound conditioning.

\section{GENERAL DISCUSSION}

The savings procedure proved to be a useful and sensitive alternative to sensory preconditioning as a measure of association among neutral stimuli. As outlined above, the savings procedure has the advantages of not requiring separate presentations of the stimulus elements involved in within-compound associations and of not demanding integration of learning acquired in different temporal and reinforcement contexts. Thus, the savings procedure might well be a more sensitive means of detecting associations among neutral stimuli than sensory preconditioning. Although we have not undertaken detailed comparisons of the sensitivity of those two procedures, it is worth noting that in an unpublished experiment in our laboratory, Kathy Allen was unable to find evidence for sensory preconditioning in this preparation when she used the same stimulus preexposure parameters as were used in Experiment 1.

Finally, it is important to note that although the behavioral observation technique used in the present experiments has the advantage of revealing a unique response generated by within-compound associations, that characteristic is not critical for the use of the savings procedure for measuring neutral stimulus associations. For example, conditioning to S1 in an S1-S2-US sequence may be hastened after
S1-S2 preexposure, especially in a situation in which S1-S2 associations are known to potentiate conditioning to $\mathrm{S} 1$ that would otherwise be acquired more slowly or not at all (e.g., Kaplan \& Hearst, 1982; Kehoe et al., 1979; Pearce et al., 1981). The use of experimental designs that assess the stimulus specificity of such effects (as in Experiment 2 of this series) would help ensure that the observed savings was due to the role of the preexposure treatment in establishing within-compound associations rather than in modulating S1's direct associations with the US, for example, by changing the extent to which S2 overshadowed S1.

\section{REFERENCES}

Adams, C., \& Dickinson, A. Actions and habits: Variations in associative representations during instrumental learning. In N. E. Spear \& R. R. Miller (Eds.), Information processing in animals: Memory mechanisms. Hillsdale, N.J: Erlbaum, 1981.

Durlach, P. J., \& Rescorla, R. A. Potentiation rather than overshadowing in flavor aversion learning: An analysis in terms of within-compound associations. Journal of Experimental Psychology: Animal Behavior Processes, 1980, 6, 175-187.

Forbes, D. T. Spontaneous configuring in conditioned flavor aversion. Unpublished doctoral dissertation, University of Pittsburgh, 1981.

Gillette, K., \& Bellingham, W. P. Loss of within-compound flavour associations: Configural preconditioning. Experimental Animal Behaviour, 1982, 1, 1-17.

Gormeznno, I., \& KEHOE, E. J. Associative transfer of classical conditioning to serial compounds. In $\mathbf{M}$. Commons, $\mathbf{R}$. Herrnstein, A. Wagner (Eds.), Quantitative analyses of behavior: Acquisition (Vol. 4). New York: Ballinger, in press.

Holland, P. C. Conditioned stimulus as a determinant of the form of the Pavlovian conditioned response. Journal of Experimental Psychology: Animal Behavior Processes, 1977, 3, 77-104.

HollaND, P. C. Second-order conditioning with and without unconditioned stimulus presentation. Journal of Experimental Psychology: Animal Behavior Processes, 1980, 6, 238-250.

Holland, P. C. Interelement associations in serial compound conditioning. In M. L. Commons, R. J. Herrnstein, \& A. R. Wagner (Eds.), Quantitative analyses of behavior: Acquisition (Vol. 3). New York: Ballinger, in press.

Holland, P. C., \& Ross, R. T. Within-compound associations in serial compound conditioning. Journal of Experimental Psychology: Animal Behavior Processes, 1981, 7, 228-241.

Kaplan, P. S., \& Hearst, E. Bridging temporal gaps between CS and US in autoshaping: Insertion of other stimuli before, during, and after CS. Journal of Experimental Psychology: Animal Behavior Processes, 1982, 8, 187-203.

Kenoe, E. J., Gibes, C. M., Garcia, E., \& Gormezano, I. Associative transfer and stimulus selection in classical conditioning of the rabbit's nictitating membrane response to serial compound CSs. Journal of Experimental Psychology: Animal Behavior Processes, 1979, 5, 1-18.

LAvin, M. J. The establishment of flavor-flavor associations using a sensory preconditioning training procedure. Learning and Motivation, 1976, 7, 173-183.

Lubow, R. E., Schnur, P., \& Rifkin, B. Latent inhibition and conditioned attention theory. Journal of Experimental Psychology: Animal Behavior Processes, 1976, 2, 163-174.

Mackintosh, N. J. The psychology of animal learning. New York: Academic Press, 1974.

Penace, J. M., Nicholas, D. J., \& Dickinson, A. The poten- 
tiation effect during serial conditioning. Quarterly Journal of Experimental Psychology, 1981, 33B, 159-179.

Razran, G. H. S. Mind in evolution. Boston: Houghton Mifflin, 1971.

Rescorla, R. A. Second-order conditioning. Hillsdale, N.J: Erlbaum, 1980. (a)

Rescorla, R. A. Simultaneous and successive associations in sensory preconditioning. Journal of Experimental Psychology: Animal Behavior Processes, 1980, 6, 207-216. (b)

RescortaA, R. A. Within-signal learning in autoshaping. Animal Learning \& Behavior, 1981, 9, 245-252.

REscorla, R. A. Some consequences of associations between the excitor and the inhibitor in a conditioned inhibition paradigm. Journal of Experimental Psychology: Animal Behavior Processes, 1982, 8, 288-298.

Rescorla, R. A., \& Cunningham, C. L. Within-compound flavor association. Journal of Experimental Psychology: Animal Behavior Processes, 1978, 4, 267-275.

Rizley, R., \& Rescorla, R. A. Associations in second-order conditioning and sensory preconditioning. Journal of Experimental Psychology: Animal Behavior Processes, 1972, 81, 1-11.
Ross, R. T., \& Holland, P. C. Conditioning of simultaneous and serial feature-positive discriminations. Animal Learning \& Behavior, 1981, 9, 293-303.

Ross, R. T., \& Holland, P. C. Serial positive patterning: Implications for "occasion-setting." Bulletin of the Psychonomic Society, 1982, 19, 159-162.

Speers, M. A., Gillan, D. J., \& Resconla, R. A. Withincompound associations in a variety of compound conditioning procedures. Learning and Motivation, 1980, 11, 135-149.

Thompson, R. F. Sensory preconditioning. In R. F. Thompson \& J. S. Voss (Eds.), Topics in learning and performance. New York: Academic Press, 1972.

WAGNER, A. R. Expectancies and the priming of STM. In S. H. Hulse, H. Fowler, \& W. K. Honig (Eds.), Cognitive processes in animal behavior. Hillsdale, N.J: Erlbaum, 1978.

Wickens, D. D., \& Cross, H. A. Resistance to extinction of temporal relations during sensory preconditioning. Journal of Experimental Psychology, 1963, 65, 206-211.

(Manuscript received August 9, 1982;

revision accepted for publication October $14,1982$. ) 